\title{
LOS ANIMALES EN EL CORÁN
}

\section{Oriol Caudevilla}

El Corán es el libro sagrado del Islam; esta afirmación por todos es sabida. No obstante, lo que mucha gente desconoce es la inmensa relación existente entre el Corán y otro libro sagrado archiconocido como la Biblia. ¿Acaso a simple vista mucha gente, al leer el texto que a continuación reproduzco, pensaría que está frente a un texto potencialmente desconocido por todos como el Corán?

"Los ángeles dijeron a María: Dios te ha escogido, te ha dejado exenta de toda mancha, te ha elegido entre todas las mujeres del universo.

¡Oh María! Sé piadosa para con tu Señor, prostérnate y dobla la rodilla ante él con los que doblan la rodilla" (Versículos 37 y 38 de la Sura II del Corán). ${ }^{1}$

Entonces, ¿por qué razón el Corán resulta tan desconocido? Las razones pueden ser varias: en primer lugar, por ser el libro sagrado de una religión que, pese a ser próxima a nosotros, no ha sido históricamente la religión mayoritaria ni en España ni en el continente europeo (esto no implica que en Europa no haya Estados cuya población sea mayoritariamente musulmana, como BosniaHerzegovina o Kosovo, sino que nunca ha sido la religión mayoritaria de Europa y, por lo tanto, nunca se le ha prestado una excesiva atención); en segundo lugar, porque mucha gente es reacia a leer los libros sagrados, considerándolos obras sin importancia, cuando en muchas ocasiones los libros sagrados, además de ser muy importante es para sus respectivos creyentes, resultan obras literarias de enorme calidad e importancia; en tercer lugar, porque, por desgracia, en los últimos 30 años, tras la Revolución Islámica de Irán en 1979, se han ido sucediendo numerosos ataques terroristas cometidos por fanáticos que falsamente utilizan el nombre del Corán para justificar sus atentados, personas que, como muy bien afirma Maalouf, "Al observar los movimientos islamistas militantes de hoy es fácil adivinar, tanto en el discurso como en los métodos, la influencia del tercermundismo de los años sesenta; en cambio, por más que busco en la historia del islam, no encuentro ningún precedente de esos movimientos. Éstos no son un producto puro de la historia musulmana, son un producto de nuestra época." ${ }^{2}$ Por lo tanto, el Corán no ampara estos movimientos ni los justifica, sino que son quienes lo quieren

\footnotetext{
${ }^{1}$ Corán, ed.Fapa, colección Ave Fénix, traducción de Yusef Omar (Barcelona 2007). Ésta es la versión que mayoritariamente he empleado para realizar este trabajo, aunque en ocasiones me voy a remitir a una edición original en árabe que en su momento citaré.

${ }^{2}$ AMIN MAALOUF, Identidades asesinas. Alianza Editorial (Madrid 2009, 3a ed).
} 
interpretar de una forma determinada quienes dan la sensación de que el Corán es algo que no es.

Esta tercera razón resulta de enormísima importancia, puesto que, por culpa de estos movimientos fanáticos, mucha gente ha adquirido animadversión al Islam, y en especial al Corán, animadversión que no debería darse, puesto que ni el Islam es una religión que proclame la violencia ni el Corán es un libro que justifique ataques terroristas; en realidad, es todo lo contrario, es la palabra de Dios (Allah o Alá) revelada al profeta Mahoma, uno de los múltiples profetas que tiene el Islam. Esta revelación se produjo a través del ángel Gabriel.

Hablar sobre el Corán podría implicar escribir por lo menos un libro entero, incluso varios libros, y aún no habríamos desvelado todos sus recovecos. No obstante, el objeto de este trabajo no es analizar el Corán en toda su amplitud, sino ver cuál ha sido la consideración que han tenido los animales en él. Y es que resulta muy interesante, en mi opinión, ver en qué términos se ha referido el Corán a los animales. Como antes he expuesto, muchos aspectos del Corán podrían ser estudiados

He estructurado este trabajo de la siguiente forma: en un primer apartado, realizaré una breve explicación acerca del Corán, en la línea de lo que he estado haciendo hasta ahora pero de forma más amplia. En los siguientes apartados me dedico a ir analizando la plasmación de distintos animales en el Corán (por ejemplo, el apartado "Los elefantes en el Corán"). En último lugar, realizo unas conclusiones acerca de todo lo visto en el trabajo. Huelga decir que hubiese resultado muy interesante, en mi opinión, realizar este trabajo en clave comparada, analizando los animales no sólo en el Corán, sino también en los textos sagrados del resto de religiones y en sus respectivas historias, aunque analizar esto hubiese dado como resultado un trabajo demasiado extenso, alejado del trabajo sucinto que pretendo realizar.

\section{EL CORAN Y EL ISLAM.}

Que el Corán es el libro sagrado del Islam es algo por todos conocido. Pero quedarnos sólo con esta afirmación es profundizar muy poco en la materia. El Corán es el libro sagrado que contiene la doctrina transmitida por Alá a los hombres a través del profeta Mahoma (Muhammad en árabe) y por intermediación del ángel Gabriel.

Mahoma no es el único profeta del Islam, sino que es el último de los profetas que Alá envió para recitar su doctrina, doctrina que según el Islam es la misma que sus predecesores habían sostenido, pero actualizada. Huelga decir que el Islam habla de la existencia de muchos más profetas anteriores a Mahoma. 


\section{Orígenes del Islam.}

La palabra Islām, de la raíz trilítera s-I-m, deriva del verbo árabe aslama, que significa literalmente 'aceptar, rendirse o someterse'. Así, el islam representa la aceptación y sometimiento ante Dios. Los fieles deben demostrar su sumisión venerándolo, siguiendo estrictamente sus órdenes y aboliendo el politeísmo.

El islam es una religión abrahámica monoteísta que adora exclusivamente a Alá sin copartícipes. Se estima que hay en la actualidad entre 1.000 y 1.200 millones de musulmanes en el mundo. Según el Vaticano el Islam (conjuntamente con todas sus ramificaciones) es la religión más extendida del mundo, ya que recientemente ha superado el número de católicos y la segunda religión del mundo si se suma el número de fieles de las distintas confesiones del cristianismo.

El islam se inició con la predicación de Mahoma en el año 622 en La Meca (en la actual Arabia Saudita). Bajo el liderazgo de Mahoma y sus sucesores, el islam se extendió rápidamente. Existe discrepancia entre los musulmanes y no musulmanes de si se extendió por imposición religiosa o militar, o por conversión de los pueblos al islam.

Dado que se trata del mismo Dios de cristianos y judíos, las cualidades que los musulmanes le atribuyen son básicamente las mismas que le atribuyen aquellos, pero hay diferencias considerables. Es reseñable, sin embargo, que el islam, a semejanza del judaísmo pero alejándose del cristianismo, insiste en su radical unidad (tawhid), es decir, que es uno y no tiene diversas personas (como afirma en cambio la mayoría de las corrientes cristianas con el dogma de la Trinidad) en su carácter incomparable e irrepresentable.

El islam se refiere a Dios también con otros noventa y nueve nombres, que son otros tantos epítetos referidos a cualidades de Dios: El Clemente (Al-Rahmān), El Apreciadísimo (Al-'Azīz), El Creador (Al-Jāliq), etc. El conjunto de los 99 Nombres de Dios recibe en árabe el nombre de al-asmā' al-husnà o 'los más bellos nombres', algunos de los cuales han sido utilizados asimismo por cristianos y judíos o han designado a dioses de la Arabia preislámica. Algunas tradiciones afirman que existe un centésimo nombre que permanece incognoscible, que es objeto de especulaciones místicas, y que se define en ocasiones como el Nombre Inmenso (ism al-'Azam), o como el Nombre de la Esencia, figura que existe igualmente en el judaísmo, y que ha tenido una gran importancia en el sufismo. Otras veces, se utiliza simplemente la palabra rabb (señor).

\section{Profetas del Islam}

Los musulmanes estiman que todos los profetas predicaban el islam, ya que solo hay un Dios. Consideran a Abraham como el primer profeta y a Mahoma 
como el último, al que le dan el título de Sello de los profetas, ya que después de él no habrá nuevas revelaciones. Los musulmanes creen que Alá ha enviado unos 124.000 mensajeros a todo el mundo, según lo mencionado en la Hadith. Cinco de ellos, conocidos como Ulul Azmi o imanes de los rasul, son reconocidos con la mayor reverencia por su inusualmente fuerte compromiso con Dios a pesar de sufrir grandes sufrimientos. Estos cinco son:

1.Nuh (Noé),

2.Ibrahim (Abraham),

3.Musa (Moisés),

4.Isa (Jesús) y

5.Muhammad (Mahoma).

Jesús es considerado como rasul porque recibió la Wahy, *a través de la cual Dios le reveló el Injil (Evangelio).

El islam atribuye a todos los profetas los siguientes atributos:

ismet: son inocentes y que no cometen actos pecaminosos.

emânet: son dignos de confianza.

fetânet: son muy inteligentes.

sidk: son siempre sinceros, jamás mienten.

teblîğ: cumplen todos los mandamientos y prohibiciones de Dios sin la menor vacilación.

\section{El Corán}

El Corán se divide en 114 capítulos denominados Suras; cada Sura está formado por versículos (en total, un poco más de 6200 versículos), cuya longitud, a lo largo del libro, va disminuyendo.

Cronológicamente, podemos distinguir dos grandes partes en el libro: los textos promulgados en La Meca y los textos promulgados en Medina. Se trata de una revelación divina, efectivamente, pero esto no nos explica por qué razón disponemos de un texto escrito. Fue el tercer califa Utman quien, alrededor del año 650, encargó la redacción del Corán.

En cuanto a su importancia, se trata de un texto básico para comprender el Islam. Sin él no podríamos entender esta religión. Como todo libro sagrado, sus preceptos pueden admitir varias interpretaciones, porque hay preceptos que pueden resultar ambiguos. Existen en el mundo musulmán los llamados comentadores que explican y/o interpretan los versículos del Corán. Pero el 
Corán debe ser leído en su contexto, no podemos leer el Corán de forma literal, desde nuestra perspectiva europea del siglo XXI, sino que debemos pensar cuál era la situación política y cultural del momento en el que fue redactadoMuchos de los versículos están relacionados con hechos que ocurrían en aquel momento o situaciones en que se encontraba Mahoma y que daban solución y/o justificación o salida a estas situaciones. Cuando el Corán, en el versículo 84 de la Sura V, afirma que: "SI hubiesen creído en Dios [los judíos], en el apóstol y en el Corán, no habrían buscado jamás la alianza de los infieles; pero

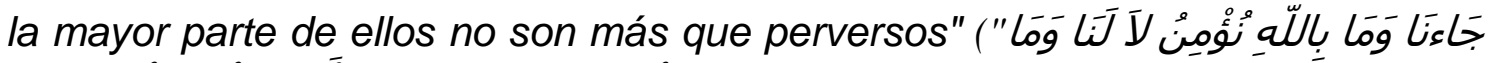

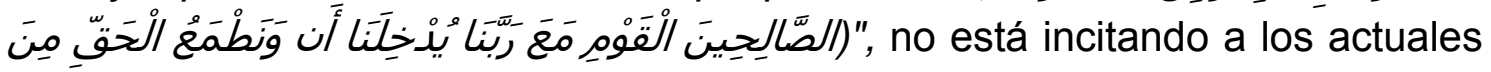
musulmanes a odiar a los judíos, como algunos interpretan, sino que simplemente está describiendo una realidad de su momento y está reflejando una intención: la realidad es que en las ciudades árabes habitaban muchos judíos, y la intención del Corán es que se conviertan al Islam, pero en ningún caso se está justificando ninguna violencia.

Ahora que ya tenemos el Corán contextualizado, pasaré a analizar qué consideración tiene el Corán de cada especie animal. Los siguientes apartados están ordenados alfabéticamente en función del nombre de la especie animal. 


\title{
II. ANIMALES CITADOS EN EL CORÁN.
}

\author{
-Abejas \\ Las abejas es el nombre que recibe la Sura 16. Se trata de las abejas al \\ versículo 68.
}

68. Tu Señor ha inspirado a las abejas: «Estableced habitación en las montañas, en los árboles y en las construcciones humanas.

\section{-Animales}

Sura 2, vers.173. Sura 5, vers.3, 4 . Sura 6,vers.38. Sura 16, vers.49, 115. Sura 22 vers.18. Sura 24 , vers. 45 .

173. Os ha prohibido sólo la carne mortecina. la sanare. la carne de cerdo y la de todo animal sobre el que se haya invocado un nombre diferente del de Alá. Pero si alguien se ve compelido por la necesidad -no por deseo ni por afán de contravenir- no peca. Alá es indulgente, misericordioso.

4. Te preguntan qué les está permitido. Di: "Os están permitidas las cosas buenas. Podéis comer de lo que os cojan los animales de presa que habéis adiestrado para la caza, tal como Alá os ha enseñado. ¡Y mencionad el nombre de Alá sobre ello! ¡Y temed a Alán. Alá es rápido en ailıstar culentas

38. No hay animal en la tierra, ni ave que vuele con sus alas, que no constituyan comunidades como vosotros. No hemos descuidado nada en la Escritura. Luego, serán congregados hacia su Señor.

115. Os ha prohibido sólo la carne mortecina, la sangre, la carne de cerdo y la de todo animal sobre el que se haya invocado un nombre diferente del de Alá. Pero, si alguien se ve compelido por la necesidad -no por deseo ni por afán de contravenir-... Alá es indulgente, misericordioso.

45. Alá ha creado a todos los animales de agua: de ellos unos se arrastran, otros caminan a dos patas, otros a cuatro. Alá crea lo que quiere. Alá es omnipotente.
3. Os está vedada la carne mortecina, la sangre, la carne de cerdo, la de animal sobre el que se haya invocado un nombre diferente del de Alá, la de animal asfixiado o muerto a palos, de una caída, de una cornada, la del devorado parcialmente por las fieras -excepto si aún lo sacrificáis vosotros-, la del inmolado en piedras erectas. Consultar la suerte valiéndose de flechas es una perversidad. Hoy quienes no creen han desesperado de vuestra religión. ¡No les tengáis, pues, miedo a ellos, sino a Mí! Hoy os he perfeccionado vuestra religión, he completado Mi gracia en vosotros y

Me satisface que sea el Islam vuestra religión. Si alguien se ve compelido durante un hambre, sin intención de pecar,... Alá es indulgente, misericordioso.

49. Lo que está en los cielos y en la tierra se prosterna ante Alá: todo animal y los ángeles. $Y$ éstos sin altivez.

18. ¿Nó ves que se prosternan ante Alá los que están en los cielos y en la tierra, así como el sol, la luna, las estrellas, las montañas, los árboles, los animales y muchos de los hombres? Esto no obstante, muchos merecen el castigo. No hay quien honre a quien Alá desprecia. Alá hace lo que Él quiere. 
-Asno

Sura 16, versículo 8. Sura 31, versículo 19. Sura 62, versículo 5. Sura 74, versículo 50. Sura 2, versículo 259.

8. Y los caballos, los mulos, los asnos, para que os sirvan de montura y de ornato. $Y$ crea otras cosas que no sabéis.

5. Aquéllos a quienes se había confiado la Tora pero no la observaron son semejantes a un asno que lleva libros. ¡Qué mal ejemplo da la gente que desmiente los signos de Alá! Alá no diriae al pueblo imbío.

49. ¿Por qué han tenido que apartarse del Recuerdo,

50. $\infty$ mo asnos espantados

51. que huven del león?
19. isé modesto en tus andares! ¡Habla en voz baja! ¡La voz más desagradable es, ciertamente, la del asno!n

259. O como quien pasó por una ciudad en ruinas. Dijo: "¿Cómo va Alá a devolver la vida a ésta después de muerta?" Alá le hizo morir y quedar así durante cien años. Luego, le resucitó y dijo: "¿Cuánto tiempo has permanecido asi?? Dijo: «He permanecido un día o parte de un dia". Dijo: "No, que has permanecido así cien años. ¡Mira tu alimento y tu bebida! No se han echado a perder. ¡Mira a tu asno! Para hacer de ti un signo para los hombres. ¡Mira los huesos, cómo los componemos y los cubrimos de carnel». Cuando lo vio claro, dijo: "Ahora sé que Alá es omnibotenten.

\section{-Bestias}

Sura 5, vers.1. Sura 2, vers.164. Sura 6, vers.138, 139, 142, 146 . Sura 11 ,vers.6. Sura 27, vers.82. Sura 29, vers.60. Sura 31, vers.10. Sura 35 ,vers.28. Sura 45, vers. 4 . Sura 81 , vers. 5 .

1. ¡Creyentes! ¡Respetad vuestros compromisos! La bestia de los rebaños os está permitida, salvo lo que se os recita. La caza no os está permitida mientras estéis sacralizados. Alá decide lo que Él quiere.

138. Y dicen: «He aquí unos rebaños y una cosecha que están consagrados. Nadie se alimentará de ellos sino en la medida que nosotros queramos". Eso pretenden. Hay bestias de dorso prohibido y bestias sobre las que no mencionan el nombre de Alá. Todo eso es una imvención contra Él. Él les retribuirá por sus invenciones.

139. $Y$ dicen: "Lo que hay en el vientre de estas bestias está reservado para nuestros varones $y$ vedado a nuestras esposas". Pero, si estuviera muerta, participarían de ella Él les retribuirá por lo que cuentan. Él es sabio, omnisciente.
164. En la creación de los cielos y de la tierra, en la sucesión de la noche y el dia, en las naves que surcan el mar con lo que aprovecha a los hombres, en el agua que Alá hace bajar del cielo, vivificando con ella la tierra después de muerta, diseminando por

ella toda clase de bestias, en la variación de los vientos, en las nubes, sujetas entre el cielo y la tierra, hay, ciertamente, signos para gente que razona.

142. De las bestias, unas sirven de carga y otras con fines textiles. ¡Comed de lo que Alá os ha proveido y no sigáis los pasos del Demonio! Es para vosotros un enemigo declarado.

146. A los judios les prohibimos toda bestia ungulada y la grasa de ganado bovino y de ganado menor, excepto la que tengan en los lomos o en las entrañas o la mezclada con los huesos. Así les retribuimos por su rebeldia. Decimos, sí, la verdad. 
6. No hay bestia sobre la tierra a cuyo sustento no provea Alá, Que conoce su madriguera y su depósito: todo está en una Escritura clara.

10. Ha creado los cielos sin pilares visibles. Ha fijado en la tierra las montañas para que ella y vosotros no vaciléis. Ha diseminado por ella toda clase de bestias. Hemos hecho bajar agua del cielo y crecer en ella toda especie generosa.

28. Los hombres, bestias y rebaños son también de diferentes clases. Sólo tienen miedo de Alá aquéllos de Sus siervos que saben. Alá es poderoso, indulgente.
82. Cuando se pronuncie contra ellos la sentencia, les sacaremos de la tierra una bestia que proclamará ante ellos que los hombres no estaban corvencidos de Nuestros signos.

60. ¡Cuántas bestias hay que no pueden proveerse del sustento! Alá se encarga de él y del vuestro. Él es Quien todo lo ove, Quien todo lo sabe.

4. En vuestra creación y en las bestias que Él esparce hay signos para gente que está convencida.

5. cuando las bestias salvajes sean agrupadas,

\section{-Caballo, corcel}

Sura 3, versículo 14. Sura 16, versículo 8. Sura 59, versículo 6, Sura 38, vers.31. Sura 100, vers.1. También recibe la sura 100 el nombre de corcel.

14. El amor de lo apetecible aparece a los hombres engalanado: las mujeres,

los hijos varones, el oro y la plata por quintales colmados, los caballos de raza, los rebaños, los campos de cultivo... Eso es breve disfrute de la vida de acá. Pero Alá tiene junto a Sí un bello lugar de retorno.

31. Cuando un anochecer le presentaron unos corceles de raza.

1. ¡Por los corceles jadeantes,

2. que hacen saltar chispas,

3. cargan el alba,
8. Y los caballos, los mulos, los asnos, para que os sirvan de montura y de ornato. $\mathrm{Y}$ crea otras cosas que no sabéis.

6. No habéis contribuido ni con caballos ni con camellos a lo que, de ellos, ha concedido Alá a Su Enviado. Alá, empero, permite a Sus emviados que dominen a quien Él quiere. Alá es omnipotente.

\section{-Camello}

Sura 7 , vers. 40,73 y 77 . Sura 11 , vers.64. Sura 12 vers. 65 y 72 . Sura 17 , vers. 59. Sura 22 , vers. 27 y 36 . Sura 26 , vers. 155 . Sura 54 , vers. 27 . Sura 56 , vers.55..Sura 59 , vers.6. Sura 77 , vers.33. Sura 81 , vers.4. Sura 91 , vers. 13 
40. A quienes hayan desmentido Nuestros signos y se hayan apartado altivamente de ellos, no se les abrirán las puertas del cielo ni entrarán en el Jardin hasta que entre un camello en el ojo de una aguja. Así retribuiremos a los pecadores.

77. $Y$ desjarretaron la camella e infringieron la orden de su Señor, diciendo: "¡Salih! ¡Tráenos aquello con que nos amenazas, si de verdad eres de los emviados!n

65. $Y$, cuando abrieron su equipaje, hallaron que se les habia devuelto su mercancía. Dijeron: «¡Padre! ¿Qué más podríamos desear? He aquí que se nos ha devuelto nuestra mercancia. Aprovisionaremos a nuestra familia, cuidaremos de nuestro hermano y añadiremos una carga de camello: será una carga ligera».

27. ¡Llama a los hombres a la peregrinación para que vengan a ti a pie o en todo flaco camello, venido de todo paso ancho y profundo,

155. Dijo: «He aquí una camella. Un día le tocará beber a ella y otro día a vosotros.

156. ¡No le hagáis mal! ¡Si no, os sorprenderá el castigo de un día terrible!

157. Pero ellos la desjarretaron... y se arrepintieron.

27. Vamos a enviarles la camella para tentarles. ¡Obsérvales y ten paciencia! 28. Infórmales de que el agua debe repartirse entre ellos y de que beberán por turno.

33. chispas que semejan camellos leonados.

4. cuando las camellas preñadas de diez meses sean descuidadas,
73. $\mathrm{Y}$ a los tamudeos su hermano Salih. Dijo: «¡Pueblo! ¡Servid a Alá! No tenéis a ningún otro dios que a Él. Os ha venido de vuestro Señor una prueba: es la camella de Alá, que será signo para vosotros, ¡Dejadla que pazca en la tierra de Alá y no le hagáis mal! Si no, os alcanzará un castigo doloroso.

64. Y, ipueblo!, ésa es la camella de Alá, que será signo para vosotros. ¡Dejadla que pazca en la tierra de Alá y no le hagáis mal! Si no, os alcanzará pronto un castigon.

72. Dijeron: «Echamos de menos la copa del rey. Una carga de camello para quien la traiga. Yo lo garantizon.

59. No Nos ha impedido obrar milagros sino que los antiguos los desmintieran. Dimos la camella a los tamudeos como milagro palpable, pero obraron impiamente con ella. No obramos los milagros sino para atemorizar.

36. Entre las cosas sagradas de Alá os hemos incluido los camellos de sacrificio. Tenéis en ellos bien. ¡Mencionad, pues, el nombre de Alá sobre ellos cuando están en fila! $Y$ cuando yazcan sin vida, comed de ellos y alimentad al mendigo y al necesitado. Así los hemos sujetado a vuestro servicio. Quizás, así, seáis agradecidos.

55. sedientos como camellos que mueren de sed...,

6. No habéis contribuido ni con caballos ni con camellos a lo que, de ellos, ha concedido Alá a Su Enviado. Alá, empero, permite a Sus emviados que dominen a quien Él quiere. Alá es omnipotente.

13. El emviado de Dios les dijo: «iDejad a la camella de Dios y que beba!n 


\section{-Cerdo}

Sura 2, vers. 173. Sura 5, vers.3.

173. Os ha prohibido sólo la carne mortecina, la sangre, la carne de cerdo y la de todo animal sobre el que se haya invocado un nombre diferente del de Alá. Pero si alguien se ve compelido por la necesidad -no por deseo ni por afán de contravenir- no peca. Alá es indulgente, misericordioso.
3. Os está vedada la carne mortecina, la sangre, la carne de cerdo, la de animal sobre el que se haya invocado un nombre diferente del de Alá, la de animal asfixiado o muerto a palos, de una caída, de una cornada, la del devorado parcialmente por las fieras -excepto si aún lo sacrificáis vosotrosla del inmolado en piedras erectas. Consultar la suerte valiéndose de flechas es una perversidad. Hoy quienes no creen han desesperado de vuestra religión. ¡No les tengáis, pues, miedo a ellos, sino a Mi! Hoy os he perfeccionado vuestra religión, he completado Mi gracia en vosotros y

Me satisface que sea el Islam vuestra religión. Si alguien se ve compelido durante un hambre, sin intención de pecar,... Alá es indulgente, misericordioso.

\section{-Elefante}

La Sura 105 recibe el nombre de "El elefante". Se hace mención en el versículo 1:

1. ¿No has visto cómo obró tu Señor con los del elefante?

\section{-Fieras}

\section{Sura 5, versículo 3.}

3. Os está vedada la carne mortecina, la sangre, la carne de cerdo, la de animal sobre el que se haya invocado un nombre diferente del de Alá, la de animal asfixiado o muerto a palos, de una caída, de una cornada, la del devorado parcialmente por las fieras -excepto si aún lo sacrificáis vosotros-, la del inmolado en piedras erectas. Consultar la suerte valiéndose de flechas es una perversidad. Hoy quienes no creen han desesperado de vuestra religión. ¡No les tengáis, pues, miedo a ellos, sino a Mí! Hoy os he perfeccionado vuestra religión, he completado Mi gracia en vosotros y 


\section{-Hormigas}

La Sura 27 toma el nombre de las hormigas.

Se nombran dos veces en la Sura 27 , vers. 18

18. Hasta que, llegados al Valle de las Hormigas, una hormiga dijo: « ¡Hormigas! ¡Entrad en vuestras viviendas, no sea que Salomón y sus tropas os aplasten sin darse cuenta!

-León

Sura 74, versículo 51.

49. ¿Por qué han tenido que apartarse

del Recuerdo,

50. como asnos espantados

51. que huyen del león?

\section{-Mariposas}

Sura 101, vers.4

4. El día que los hombres parezcan mariposas dispersas

\section{-Mosca}

Sura 22, vers.73

73. ¡Hombres! Se propone una parábola. ¡Escuchadla! Los que imvocáis en lugar de irrocar a Alá serian incapaces de crear una mosca, aun si se aunaran para ello. $Y$, si una mosca se les llevara algo, serían incapaces de recuperarlo. ¡Qué débiles son el suplicante $y$ el sublicado! 


\section{-Monos}

Se nombran los monos en 3 versículos:

Sura 2, versículo 65. Sura 5, versículo 60. Sura 7, versículo 166.

65. Sabéis, ciertamente, quiénes de vosotros violaron el sábado. Les dijimos: «iConvertíos en monos repugnantes!

166. $\mathrm{Y}$, cuando desatendieron las prohibiciones, les dijimos: «iCorvertios en monos repugnantes!»
60. Di: «No sé si informaros de algo peor aún que eso respecto a una retribución junto a Alá. Los que Alá ha maldecido, los que han incurrido en Su ira, los que Él ha convertido en monos y cerdos, los que han servido a los taguts, ésos son los que se encuentran en la situación peor y los más extraviados del camino recton.

\section{-Mulos}

\section{Sura 16, versículo 8}

8. Y los caballos, los mulos, los asnos, para que os sirvan de montura y de ornato. $Y$ crea otras cosas que no sabéis.

\section{-Ovejas}

Sura 21, vers.78. Sura 38, vers. 23 y 24.

78. $Y$ a David y Salomón. Cuando dictaron sentencia sobre el sembrado en que las ovejas de la gente se habian introducido de noche. Nosotros fuimos testigos de su sentencia.
23. Este es mi hermano. Tiene noventa y nueve ovejas y yo una oveja. Dijo: '¡Confiamela!' Y me gana a discutir".

24. Dijo: «Si, ha sido injusto contigo pidiéndote que agregaras tu oveja a las suyas". En verdad, muchos consocios se causan daño unos a otros; no los que creen y obran bien, pero iqué pocos son éstos! David comprendió que sólo habiamos querido probarle y pidió perdón a su Señor. Cayó de rodillas y se arrepintió. 25. Se lo perdonamos y tiene un sitio junto a Nosotros y un bello lugar de retorno. 


\section{-Pájaros}

Sura 3, vers. 49 y 110. Sura 12, vers. 36 y 41 . Sura 27, vers. $16,17,20$. Sura 34 , vers.10. Sura 38 , vers. 19

49. $\mathrm{Y}$ como emviado a los Hijos de Israel: "Os he traido un signo que viene de vuestro Señor. Voy a crear para vosotros, de la arcilla, a modo de pájaros. Entonces, soplaré en ellos y, con permiso de Alá, se comvertirán en pájaros. Con permiso de Alá, curaré al ciego de nacimiento $y$ al leproso $y$ resucitaré a los muertos. Os informaré de lo que coméis y de lo que almacenáis en vuestras casas. Ciertamente, tenéis en ello un signo, si es que sois creyentes.

36. Con él, entraron en la cárcel dos esclavos. Uno de ellos dijo: «Me he visto prensando uvan. Y el otro dijo: "Yo me he visto llevando sobre la cabeza pan, del que comian los pájaros. ¡Danos a conocer su interpretación! Vemos que eres de quienes hacen el bien.

20. Pasó revista a los pájaros y dijo: "¿Cómo es que no veo a la abubilla? ¿O es que está ausente?

19. Y los pájaros, en bandadas. Todo vuelve a Él.
110. Cuando dijo Alá: «jJesús, hijo de Maria! Recuerda Mi gracia, que os dispensé a ti y a tu madre cuando te fortalecí con el Espíritu Santo y hablaste a la gente en la cuna y de adulto, y cuando te enseñé la Escritura, la Sabiduría, la Tora y el Evangelío. Y cuando creaste de arcilla a modo de pájaros con Mi permiso, soplaste en ellos y se convirtieron en pájaros con Mi permiso. Y curaste al ciego de nacimiento y al leproso con Mi permiso. $Y$ cuando resucitaste a los muertos con Mi permiso. $\mathrm{Y}$ cuando alejé de ti a los Hijos de Israel cuando viniste a ellos con las pruebas claras y los que de ellos no creian dijeron: 'Esto no es sino manifiesta magia'.

41. ¡Compañeros de cárcel! Uno de vosotros dos escanciará vino a su señor. El otro será crucificado y los 10. Dimos a David un favor Nuestro: «iMontañas! ¡Resonad acompañándole, y vosotros también, pájaros!n Por él, hicimos blando el hierro.

\section{-Perro}

El perro es citado en tres versículos:

A la Sura 7, versículo 176:

176. Si hubiéramos querido, le habríamos levantado con ellos. Pero se apegó a la tierra y siguió su pasión. Pasó con él como pasa con el perro: jadea lo mismo si le atacas que si le dejas en paz. Así es la gente que desmiente Nuestros signos. Cuéntales estas cosas. Quizás, así, reflexionen.

A la Sura 1, versículos 18 y 22:

18. Les hubieras creido despiertos cuando, en realidad, dormian. Les dábamos vuelta a derecha $e$ izquierda, mientras su perro estaba en el umbral con las patas delanteras extendidas. Si les hubieras visto, te habrías escapado de ellos, lleno de miedo.
22. Unos dirán: «Eran tres, cuatro con su perro". Otros dirán: "Eran cinco, seis con su perron, conjeturando sobre lo oculto. Otros dirán: «Eran siete, ocho con su perro". Di: «Mi Señor sabe bien su número, sólo pocos les conocen*. No discutas, pues, sobre ellos, sino someramente y no consultes sobre ellos a nadie. 


\section{-Pez, Peces}

Sura 7 , vers.163. Sura 18 , vers.61 y 63 . Sura 21 , vers.87. Sura 37 vers.142. Sura 68 , vers. 48

163. Y pregúntales por aquella ciudad, a orillas del mar, cuyos habitantes violaban el sábado. Los sábados venian a ellos los peces a flor de agua y los otros días no venían a ellos. Les probamos así por haber obrado perversamente.

87. $\mathrm{Y}$ al del pez. Cuando se fue airado y creyó que no podríamos hacer nada contra él. $\mathrm{Y}$ clamó en las tinieblas: «jNo hay más dios que Tú! ¡Gloria a Ti! He sido de los impíos».

48. Espera, pues, paciente la decisión de tu Señor y no hagas como el del pez, cuando clamó en medio de la angustia.

\begin{abstract}
61. $Y$, cuando alcanzaron su confluencia, se olvidaron de su pez, que emprendió tranquilamente el camino hacia la gran masa de agua.
\end{abstract}

63. Dijo: «¿Qué te parece? Cuando nos refugiamos en la roca, me olvidé del pez - nadie sino el Demonio hizo olvidarme de que me acordara de ét-y emprendió el camino hacia la gran masa de aqua. ¡Es asombroso!n

142. El pez se lo tragó, habia incurrido en censura.

\section{-Rebaños}

Sura 5, vers.1, 95. La Sura 6 recibe el nombre de rebaños. Sura 6, vers.136 y 138. Sura 7, vers.179. Sura 10, vers. 24. Sura 16, vers. 5, 66, 80. Sura 20, vers.18, 54. Sura 22, vers. 30. Sura 23, vers. 21. Sura 25, vers. 44, 49. Sura 26, vers. 133. Sura 28, vers.23, 24, 25. Sura 32, vers.27. Sura 35, vers. 28 . Sura 36, vers.71. Sura 39, vers. 6. Sura 40, vers.79. Sura 41, vers.11, Sura 43, vers.12. Sura 70 , vers.33. Sura 80 , vers. 32 .

1. ¡Creyentes! ¡Respetad vuestros compromisos! La bestia de los rebaños os está permitida, salvo lo que se os recita. La caza no os está permitida mientras estéis sacralizados. Alá decide lo que Él quiere.

136. Reservan a Alá una parte de la cosecha y de los rebaños que Él ha hecho crecer. $Y$ dicen: "Esto es para Alá" -eso pretenden- "y esto para nuestros asociados". Pero lo que es para quienes ellos asocian no llega a Alá y lo que es para Alá llega a quienes ellos asocian. ¡Qué mal juzgan!

179. Hemos creado para la gehena a muchos de los genios y de los hombres. Tienen corazones con los que no comprenden, ojos con los que no ven, oídos con los que no oyen. Son como rebaños. No, aún más extraviados. Esos tales son los que no se preocupan.
95. ¡Creyentes! No matéis la caza mientras estéis sacralizados. Si uno de vosotros la mata deliberadamente, ofrecerá como víctima a la Caaba, en compensación, una res de su rebaño, equivalente a la caza que mató -a juicio de dos personas justas de entre vosotros-, o bien expiará dando de comer a los pobres o ayunando algo equivalente, para que guste la gravedad de su conducta. Alá perdona lo pasado, pero Alá se vengará del reincidente. Alá es poderoso, vengador.

138. $\mathrm{Y}$ dicen: «He aquí unos rebaños y una cosecha que están consagrados. Nadie se alimentará de ellos sino en la medida que nosotros queramos». Eso pretenden. Hay bestias de dorso prohibido y bestias sobre las que no mencionan el nombre de Alá. Todo eso es una imvención contra Él. Él les retribuirá por sus invenciones. 
24. La vida de acá es como agua que hacemos bajar del cielo. Las plantas de la tierra se empapan de ella y alimentan a los hombres y a los rebaños, hasta que, cuando la tierra se ha adornado y engalanado, y creen los hombres que ya la dominan, llega a ella Nuestra orden, de noche o de dia, y la dejamos cual rastrojo, como si, la víspera, no hubiera estado floreciente. Así explicamos los signos a gente que reflexiona.

80. Ala os ha necho de vuestras viviendas un lugar habitable. De la piel de los rebaños os ha hecho tiendas, que encontráis ligeras al trasladaros o al acampar. De su lana, de su pelo y de su crin, artículos domésticos para disfrute por algún tiempo.

30. ¡Así ešl Y quien respete las cosas sagradas de Alá, será mejor para él ante su Señor. Se os han declarado lícitos los rebaños, excepto lo que se os recita. ¡Evitad la contaminación que viene de los ídolos! ¡Evitad el decir falsedades!

44. ¿Crees que la mayoría oyen o entienden? No son sino como rebaños. No, más extraviados aún del Camino.

132. iTemed a Quien os ha proveído de lo que sabéis:

133. de rebaños e hijos varones,

24. $Y$ abrevó su rebaño. Luego, se retiró a la sombra. $Y$ diio: «iSeñor! Me hace mucha falta cualquier bien que quieras hacermen.

25. Una de las dos vino a él con paso tímido y dijo: «Mi padre te llama para retribuirte por habernos abrevado el rebañon. Cuando llegó ante él y le contó lo que le habia ocurrido, dijo: «iNo temas! Estás a salvo del pueblo impion.

28. Los hombres, bestias y rebaños son también de diferentes clases. Sólo tienen miedo de Alá aquéllos de Sus siervos que saben. Alá es poderoso, indulgente.

6. Os ha creado de una sola persona, de la que ha sacado a su cónyuge. Os ha dado, de los rebaños, cuatro parejas. Os ha creado en el seno de vuestras madres, creación tras creación, en triple oscuridad. Tal es Alá, vuestro Señor. Suyo es el dominio. No hay más dios que Él. ¡Cómo, podéis pues, ser tan desviados!
5. $\mathrm{Y}$ los rebaños los ha creado para vosotros. Hay en ellos abrigo y otras ventajas y os alimentáis de ellos.

66. $Y$ en los rebaños tenéis motivo de reflexión. Os damos a beber del contenido de sus vientres, entre heces y sangre: una leche pura, grata a los bebedores.

18. "Es mi vara", dijo. "Me apoyo en ella y con ella vareo los árboles para alimentar a mi rebaño. También la empleo para otros usos:.

54. ¡Comed y apacentad vuestros rebaños! Hay, en ello, ciertamente, signos para los dotados de entendimiento.

21. Tenéis, ciertamente, en los rebaños motivo de reflexión: os damos a beber del contenido de sus vientres, deriváis de ellos muchos beneficios, coméis de ellos.

49. para vivificar con ella un paîs muerto y dar de beber, entre lo que hemos creado, a la multitud de rebaños $v$ seres humanos.

23. Cuando llegó a la aguada de Madián, encontró allí a un grupo de gente que abrevaba sus rebaños. Encontró, además, a dos mujeres que mantenian alejado el de ellas. Dijo: "¿Qué os pasa?" Dijeron ellas: "No podemos abrevar el rebaño mientras estos pastores no se lleven los suyos. $Y$ nuestro padre es muy ancianon.

27. ¿Es que no ven cómo conducimos el agua a la tierra pelada y, gracias a ella, sacamos los cereales de que se alimentan sus rebaños y ellos mismos? ¿No verán, pues?

71. ¿Es que no ven que, entre las obras de Nuestras manos, hemos creado a su intención rebaños que les pertenecen?

79. Alá es Quien ha puesto para vosotros los rebaños, para que montéis en unos y de otros os alimentêis, 
11. Creador de los cielos y de la tierra. Os ha dado esposas salidas de vosotros y parejas salidas de vuestros rebaños, diseminándoos así. No hay nada que se Le asemeje. Él es Quien todo lo oye, Quien todo lo ve.
12. Quien ha creado todas las parejas y os ha dado las naves y los rebaños en que montáis,

33. Para disfrute vuestro y de vuestros rebaños.

32. para disfrute vuestro y de vuestros rebaños.

\section{-Serpiente}

Sura 7 , vers.107, Sura 20, vers.20. Sura 26, vers.32. Sura 27, vers.10. Sura 28, vers.31,

107. Tiró su vara y se convirtió en auténtica serpiente.

32. Moisés tiró su vara y he aquí que ésta se convirtió en una auténtica serpiente.

31. ¡Tira tu vara!» $Y$ cuando vio que se movía como si fuera una serpiente, dio media vuelta para escapar, sin volverse. «¡Moisés! ¡Avanza y no temas! iNo va a pasarte nada!
20. Là tiró y he aquí que se corvirtió en una serpiente que reptaba.

10. $Y$ : «iTira tu vara!» $Y$ cuando vio que se movia como si fuera una semiente, dio media vuelta para escapar, sin volverse. «¡Moisés! ¡No tengas miedo! Ante Mí, los enviados no temen. 


\section{III.CONCLUSIONES}

Como hemos visto, el Corán es un texto sagrado mucho más cercano a nosotros de lo que podríamos pensar inicialmente. Está ampliamente emparentado con los libros sagrados previos, el Pentateuco y Los Evangelios, de los cuales se habla en numerosas ocasiones en el Corán. Aunque uno no sea musulmán, no debe obviarse la importancia de este texto no sólo en la cultura árabe, sino en toda la cultura del muchas veces denominado "mundo musulmán", que se extiende desde Marruecos (el país con mayoría de población musulmana situado más al occidente) hasta Indonesia, pasando por países tan diversos como Egipto, Arabia Saudí, Uzbekistán, Malasia... No debemos olvidar que no sólo ha influido en su cultura, sino que también ha influido en su cultura jurídica. Sin ir más lejos, el Corán es la Constitución de Arabia Saudí.

Por lo tanto, considero que la primera y más importante conclusión es que el Corán no es un libro lejano, sino próximo. pero el objetivo del trabajo, como hemos visto, no era sólo éste. El objetivo era ver cuál es el papel de los animales en el Corán. Huelga decir, aunque quizás a estas alturas del trabajo sea innecesario, que el trabajo se titula "Los animales en el Corán" y no "Los animales en el Islam". ¿Por qué esta distinción? Esta distinción es importante a efectos prácticos, porque es distinto una cosa de la otra. En el Corán se habla de algunos animales de forma superficial, mientras que el Islam contiene en su conjunto regulaciones más amplias.

Por ejemplo, como hemos visto, el Corán habla de los perros, pero no de forma muy amplia. En cambio, sabemos que en el Islam el perro es un animal hacia el cual no se le tiene mucha simpatía. Éstas son cuestiones que provienen de otras fuentes, de la interpretación que han realizado los sabios estudiosos del Corán. $Y$ en este tema ya no puedo entrar, porque esto conllevaría a realzar un trabajo muchísimo más extenso. Mi trabajo, por lo tanto, se ha centrado en de qué forma se citan y de qué forma se tratan algunos animales relevantes en el Corán.

El animal que más veces se cita es el camello; esto es lógico, puesto que es un animal que tenía una importancia muy grande en la época en que fue revelado el Corán.

En cualquier caso, espero que este trabajo haya servido para acercar un poco el Corán, para intentar incentivar su lectura, puesto que se trata de un libro muy importante y que debe ser leído. 


\section{IV..BIBLIOGRAFÍA.}

ed. Al-Alami. 2007, Beirut.

Corán, ed.Fapa, colección Ave Fénix, traducción de Yusef Omar (Barcelona 2007).

RICHARD C.FOLTZ . Animals in Islamic Tradition and Muslim Cultures. Oneworld Publications, 2006.

AMIN MAALOUF, Identidades asesinas. Alianza Editorial (Madrid 2009, 3a ed).

AL-HAFIZ BASHEER AHMAD MASRI. Animal Welfare in Islam, 1993.

LIVIO TESCAROLI, El Corán y el Islam Madrid. Ed.Bruño, 1980

VVAA. Encyclopédie de I'Islam . E.J. Brill, Leiden 1960-2009 